\title{
Culturally Sensitive Communication in Healthcare (a Case study of therapeutic communication between doctor-patient and family in Sundanese region)
}

\author{
Susanne Dida ${ }^{1}$ Rostika Yuliani ${ }^{2}$, Elnovani Lusiana ${ }^{3}$, Evi Novianti $^{4}$ \\ \{ susanne.dida@unpad.ac.id $^{1}$, Rostika12001@mail.unpad.ac.id $\left.{ }^{2}\right\}$ \\ ${ }^{1,2,3,4}$ Universitas Padjadjaran, Indonesia
}

\begin{abstract}
Research on sensitive cultural communication in health services never runs out of topics, and there is always something exciting to study. One of the fascinating researches focuses on uncovering therapeutic communication between doctors, patients, and families in West Java, a place where the second largest ethnic group in Indonesia resides with a variety of cultural sensitivity in the health sector. The purpose of this study is to identify and explore the sensitive cultural aspects, which is hampering therapeutic communication between doctors, patients, and their families that cause misunderstanding between them while finding solutions to overcome them. The theory used in this research is the therapeutic communication theory with concepts and sensitive cultural approaches. The method chosen is a case study with an exploratory approach, which is expected to help explore this problem. The result shows that each culture has differences and its uniqueness, including on sensitive matters and some different individuals' perspectives from different cultures, in the form of myths, pamali, and other restrictions that only apply to a particular culture. A scientific approach can overcome sensitive culture through the competency of doctors or health workers because they are considered to be very adaptive to change, as mandated and regulated by the RI Health Law. This research is expected to help health workers, such as doctors, to ready when placed on duty wherever they are needed.
\end{abstract}

Keywords: Health, Sensitive culture, Therapeutic communication, West Java culture.

\section{Background}

Several factors affect a person's health status, namely the environment, both physical and social, social environment can affect one's behavior. Humans, as social beings, are interdependent with one another within their social environment, in solving various individual problems and social problems that occur. Likewise, the Sundanese in the past, even now, in how they maintain their health. Culture is closely related to one's experience, including during their sickness or taking medication.

By examining some of the patient's experiences after returning from doctor treatment, hoping to know the illness they suffered, they feel disappointed as the information on the illness is not being shared with the patient. When the family asked about the patient's illness, they could not say it with certainty. They think hard what the doctor said earlier, "... ... the term is strange, things like the medical term that I do not know, it was unclear ...", those are most of the answers from the patient to the family.

This supposed communication event might be part of a doctor's ethical code in not rushing into a conclusion on patient complaints without further check and recheck with laboratory examinations, administering drugs, and other actions.

Other communication events occur as many families of patients who feel confused when doctors call upon them as a family representative in order to talk seriously about an important 
decision on the final condition of the patient's real health. They are worried, there are even family members who cry and depressed when they hear the doctor's decision.

The doctors also have this unease feeling, as the person in charge of the patient's health, they feel the difficulty in delivering the information to the patient or patient's family. The example of saying sensitive decisions such as a patient's health condition that has gotten worse, must have a dialysis treatment, and other terminal conditions.

The examination of the experience on a patient-doctor communication shows that it is indeed very sensitive, and complicated because it involves various elements and requires communication skills. It also needs to consider aspects of psychology, culture, sociology, language, religion, behavior, and other ethics.

Cultural sensitivity is being aware that cultural differences and similarities between people exist without assigning them a value - positive or negative, better or worse, right or wrong.

Some cultural competencies must be mastered by medical staff in dealing with patients because health services will significantly affect the needs and health status of patients who have different cultures. Some aspects to consider are as follows: demographics, culture, healthy behavior, language, risk factors, and diseases suffered. Another thing to consider is the different health perspectives in particular ethnicity, or religions such as Taoism, Islam, Buddhism, and other religions. The study of sensitive communication is related to the interaction of doctors, patients, and families.

There are numbers of sensitive communication problems that occur from patients' point of view when they receive treatment; the problems include both cultural and religious aspects in the community of West Java / Sundanese region including:

Table 1. Numbers of Sensitive Communication Problems That Occur from Patients' Point of View When They Receive Treatment

\begin{tabular}{|c|c|c|c|c|}
\hline No & Situation & Sensitive Culture & Obstacle/Barrier & Doctor's Action \\
\hline 1 & $\begin{array}{l}\text { Pregnant mom in the } \\
\text { third trisemester }\end{array}$ & $\begin{array}{l}\text { Do not want to see } \\
\text { picture/talk on } \\
\text { frightening matters } \\
\text { or related to blood }\end{array}$ & Culture & $\begin{array}{l}\text { Doctor should find } \\
\text { another alternative to } \\
\text { deliver the message } \\
\text { without picture. }\end{array}$ \\
\hline 2 & $\begin{array}{l}\text { Pregnant mom in } \\
\text { early pregnancy or } \\
\text { first trisemester }\end{array}$ & $\begin{array}{l}\text { Cannot talk about } \\
\text { her pregnancy }\end{array}$ & Culture & Keep it as a secret \\
\hline 3 & $\begin{array}{l}\text { The disease on the } \\
\text { patient has reach } \\
\text { terminal stage }\end{array}$ & $\begin{array}{l}\text { Cannot talk directly } \\
\text { to the patient }\end{array}$ & Culture & Talk to patient's family \\
\hline 4 & $\begin{array}{l}\text { Cervix examination } \\
\text { in Obstetrics \& } \\
\text { Gynecology chair }\end{array}$ & $\begin{array}{l}\text { Reproductive can be } \\
\text { seen by doctor and } \\
\text { assistant }\end{array}$ & $\begin{array}{l}\text { Religion } \\
\text { Culture }\end{array}$ & $\begin{array}{l}\text { Should start the process } \\
\text { with "Bismillah" and } \\
\text { permission to close up the } \\
\text { examination area }\end{array}$ \\
\hline 5 & $\begin{array}{l}\text { Mom with } \\
\text { "disgusting illness" } \\
\text { such as Leukorea }\end{array}$ & $\begin{array}{l}\text { Reproductive tools } \\
\text { should be clean or } \\
\text { other action }\end{array}$ & Psychology & $\begin{array}{l}\text { Doctor should not show a } \\
\text { disgusted face and } \\
\text { condemning statement }\end{array}$ \\
\hline 6 & $\begin{array}{l}\text { Elderly patient with } \\
\text { hearing difficulties }\end{array}$ & $\begin{array}{l}\text { Do not comment and } \\
\text { talk loudly }\end{array}$ & Culture & $\begin{array}{l}\text { Try some assistance from } \\
\text { family or picture to } \\
\text { communicate }\end{array}$ \\
\hline
\end{tabular}




\begin{tabular}{|c|c|c|c|c|}
\hline 7 & $\begin{array}{l}\text { Placenta from the } \\
\text { newly born baby }\end{array}$ & $\begin{array}{l}\text { Placenta is asked to } \\
\text { bring home to be } \\
\text { buried }\end{array}$ & Culture & $\begin{array}{l}\text { Allow it, tell them how to } \\
\text { bury it. }\end{array}$ \\
\hline 8 & $\begin{array}{l}\text { The tradition of } \\
\text { adding scissor/small } \\
\text { knife as clothing } \\
\text { accessories for } \\
\text { pregnant mom }\end{array}$ & $\begin{array}{l}\text { Protection for the } \\
\text { fetus from harm and } \\
\text { evil spirits }\end{array}$ & Culture & $\begin{array}{l}\text { Should be kept in a bag to } \\
\text { be secured }\end{array}$ \\
\hline 9 & $\begin{array}{l}\text { People with Flu, and } \\
\text { smallpox cannot } \\
\text { take a bath }\end{array}$ & $\begin{array}{l}\text { Taking a bath invites } \\
\text { fever for patient }\end{array}$ & Myth/Culture & $\begin{array}{l}\text { Explain how to take bath } \\
\text { with this disease }\end{array}$ \\
\hline 10 & $\begin{array}{l}\text { "Masuk Angin" } \\
\text { should be treated by } \\
\text { "Kerokan" }\end{array}$ & $\begin{array}{l}\text { To get the "wind" } \\
\text { out }\end{array}$ & Culture & $\begin{array}{l}\text { Give the explanation } \\
\text { about the harm of } \\
\text { performing "kerokan". }\end{array}$ \\
\hline 11 & $\begin{array}{l}\text { Breastfeeding mom } \\
\text { should not eat fish as } \\
\text { the breastfeed would } \\
\text { smell fishlike }\end{array}$ & $\begin{array}{l}\text { Fish has a particular } \\
\text { aroma }\end{array}$ & Myth/Culture & $\begin{array}{l}\text { Explain the benefit of fish } \\
\text { for breastfeeding mom }\end{array}$ \\
\hline 12 & Patient has TBC & $\begin{array}{l}\text { The stigma for this } \\
\text { illness is terrifying } \\
\text { and the patient } \\
\text { should be isolated }\end{array}$ & Socio-culture & $\begin{array}{l}\text { Emphaty, deliver the } \\
\text { detailed information to } \\
\text { patient and family, also } \\
\text { the surrounding }\end{array}$ \\
\hline 13 & Leprosy patient & $\begin{array}{l}\text { Social stigma as it is } \\
\text { considered as cursed } \\
\text { illness }\end{array}$ & Socio-culture & $\begin{array}{l}\text { Emphaty, deliver the } \\
\text { detailed information to } \\
\text { patient and family, also } \\
\text { the surrounding }\end{array}$ \\
\hline
\end{tabular}

There are several concepts of cultural communication related to sensitive matters, identification of their implications for the practical world of health. Intercultural communication is essential to be learned by health practitioners, doctors, and other health workers because it involves trust from patients, patient compliance, and patient recovery.

Attitude to illness, kinds of treatment, the role of the doctor, and his / her relationship to the patient varies widely across cultures. What is considered an illness in one culture may not be seen as such in another. Some cultures favor treatment of the whole person, other concentrates on dealing with specific symptoms. In some cultures, the doctor will put more emphasis on the patient as a person, while in others the focus is on analyzing the illness[1].

Although a professional code of ethics universally bounds doctors, but in principle, a doctor must fulfill ethical principles: Medical Ethics is based on four ethical principles, namely respect for autonomy, non-maleficence, benefit, and justice[2].

In line with the ethics of Indonesian Medical, which reads:

(The ethical and professional attitude of the doctor is autonomy (respecting the patient's rights), beneficence (taking action for the good of the patient), non-maleficence (not doing actions that aggravate the patient), justice (being fair and honest), altruism (professional service)[3].

Doctors and health workers realize that the beliefs, values, attitudes, and behaviors of a culture can be learned and anticipated by doctors and health workers for the sake of this noble humanitarian profession.

Indonesia with its collectivist culture has a unique behavior when dealing with the medical world. Several other habits are no less unique and sensitive, including,

- When patients go to the doctor often accompanied by his family 
- When the patient is hospitalized, the family will be accompanying patient

- When the patient goes to operation, he/she will be prayed and accompanied by family

- When patients are hospitalized, many friends would visit and give support.

- When the patient is in the hospital, the family will bring the patient's favorite foods and bring pillowcases and blankets that are commonly worn by patients.

Those habits should encourage medical practitioners to provide a quality health service, as mentioned by Al-Muqsith "the quality of health services should not be affected by and sensitive communication culture, but it should be negotiated to achieve optimal results, [3]"

Many aspects can be considered by doctors or medical personnel when they encounter sensitive matters that need to be communicated to patients and families. Among others, the problem of medical costs and action costs to cure patients, as well as how to pay. And also the need to consider how to express things that are sensitive to patients, families who need medical treatment as soon as possible. Religious influences and pamali perceptions need to be taken into consideration as well as other aspects, such as the effect of medical treatment or action on patients.

\section{Research methods}

The right method for this research is an explanatory case study in order to explore the case of sensitive cultural communication between patient-doctor-family in West Java. This study can further explain the impact of sensitive cultural communication carried out by doctors or health care workers in the treatment process for their patients.

Culturally sensitive health care has been described as care that reflects "the ability to be appropriately responsive to the attitudes, feelings, or circumstances of groups of people that share a common and distinctive racial, national, religious, linguistic, or cultural heritage"[4].

The research is essential for a multi-ethnic society such as Indonesia, which has a culture with its uniqueness and sensitivity. This research is interesting as to avoid further misunderstandings, reduce misunderstandings, and refraining from conflicts that are not beneficial either to the doctor or the patient. Moreover, doctors or health workers are required to have competence when faced with patients from multicultural background.

Respect is at the heart of cultural competence-patients who feel their healthcare providers respect their beliefs, customs, values, language, and traditions are more likely to communicate freely and honestly, which can, in turn, reduce disparities in healthcare and improve patient outcomes.

This study, specifically, explores cases of sensitive culture in West Java society related to health aspects, with the following research analysis units:

- The type of sensitive culture of West Java that prevents people from undergoing treatment both in the form of myths, pamali, and other prohibitions

- Community perception about sensitivity culture

- Doctor's perception of sensitive culture as a provider of health services

- The efforts of doctors to overcome the cultural barriers of the West Javanese community

- Therapeutic communication model/concept in overcoming the sensitive cultural barriers of West Java society. 
- $\quad$ Data collection process carried out:

- Interviews with doctors, patients, and their families

- Literature studies from various works of literature on sensitive culture, therapeutic communication, and journals related to therapeutic communication, sensitive culture and articles on health policy and medical ethics

- Observation is carried out by observing therapeutic communication between doctors and patients in practice, with various patient complaints.

The research subjects were direct informants, namely three doctors, thirteen patients, and seven family members of patients who treated at five hospital patients, six Puskesmas (Centre of Health for Society) patients, and two private practice doctors.

\section{Research Results, Discussion}

How to reduce cultural disparities and therapeutic communication gaps between doctors and patients in achieving optimal health care is essential for the health care system in Indonesia. Specifically, sensitive therapeutic communication competencies should be seen as a basic pillar to reduce disparities in the quality of care for patients with cultural sensitivity to prevent biased views. Culturally competent services are defined as services that respect the patient's ethnic background, cultural diversity, and other cultural factors that can influence health services such as language, communication style, beliefs, attitudes, and behavior. The Ministry of Health of the Republic of Indonesia establishes ethics for services that are culturally appropriate and within a shared value among the community.

The various challenges regarding therapeutic communication that require cultural competence still exist. At present many obstacles are found on the diversity of sensitive cultures, and some previous research is very helpful in establishing the solution.

- A type of sensitive culture that prevents people from taking medication to doctors. There is still a division of medical treatment, and people choose when to go to the doctor and when to go to a shaman, paraji, or other alternative treatments. They go to the doctor if their complaints are physical, can be seen, can be touched, can be treated with drugs, and can be proven by tests in the laboratory. Several types of sensitive cultures become barriers to doctor-patient communication, including third-trimester pregnant women who do not want to hear and see the risk of pregnant women and dangerous birthmarks. The solution is that the information can be conveyed to pregnant mom's families, then the family would try to remind and monitor pregnant moms in their native language and culture.

- Community perceptions about their sensitive culture.

Culture is hereditary, and it becomes the concern of the people who live within the culture and is overseen by the cultural guardian elders - this sensitive culture is in the form of pamali, ban, curses, oaths, and many more. Until now, some sensitive cultures still exist in West Java culture, for example, not spreading the news of the pregnancy before the fetus is three months old, if it is violated, it can cause a fetus to miscarry, the myth which many obstetricians already knew.

- Doctor's perception of sensitive culture as a service provider. 
Some myths can be negotiated, for example, a family member who has just given birth will immediately ask for the placenta after the baby is born to be buried/dissolved based on local cultural habits and rituals usually led by a paraji.

- Doctors' efforts to reduce sensitive cultural barriers.

Through an approach of empathy, these unfavorable habits can be overcome and discussed with patients. The doctor must adapt to the environment in which he/she lives and learns the local wisdom of the local culture in order to gain the sympathy and trust from the local community.

- Therapeutic communication model/concept in overcoming sensitive cultural barriers, mutually beneficial efforts, for the sake of humanity and the noble duty of doctors to improve public health.

Sensitive cultural communication competencies are often seen to only include differences in values and ethnicity, even though the problem is more complicated than that. Therefore, therapeutic communication competence for sensitive matters of culture needs to be mastered. The goal of therapeutic communication is to help patients feel cared for and understood and to build relationships in which patients would feel free to express their concerns to the doctor[5].

\section{Perception Influences Respect for Culture}

Leprosy patients in West Java will hide when seen or bump into people, and they will be furious if doctors or anyone spread their disease information because leprosy is considered a curse, even though it is just a hereditary perception.

The relationship between perception and cultural background, is one form of information processing, besides sensation, memory, and thinking.

The relationship between perception and cultural background is the process of giving meaning to sensations so that humans acquire new knowledge. In other words, the relationship between perception and the cultural background turns sensation into information[6].

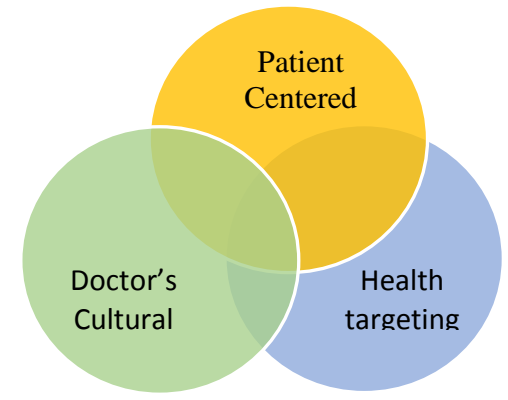

Figure 1. The therapeutic communication concept of doctors, patients/families, and health targets. This concept includes three circles namely the doctor's cultural competency circle, the patient's cultural circle, and the health target circle describing,

- Characteristics of patients and family members with cultural backgrounds are aware of the uniqueness and cultural sensitivity in many ways, including in the health sector. Myth, pamali, and the prohibition of hereditary culture existed and still performed if it has benefits, but gradually, along with the increase in education, that sensitive culture 
fades. However, beliefs and myths in older people are still performed with dedication, as stated by informants SA, SM, IF.

- Doctors' cultural competence can improve and provide health services to patients from various cultures. Many things doctors can do to improve cultural competence to the sensitive culture of a society. As health professionals are required to make regular contact with patients, specifically for patients under the supervision of a doctor.

- As indicated by the circle of health targets, there are ongoing interventions both by doctors as the spearhead of coverage in meeting healthy Indonesia 2020 and SDG targets. All efforts and various socialization are carried out on various occasions at all levels of society so that the health status of West Java would increase exponentially Under the target of the Human Development Index of West Java Regional Government.

\section{Conclusion}

When doctors manage to understand the condition of patients and their families, starting with the first meeting and continue throughout the service/treatment of patients and enabling dialogical communication without cultural barriers, psychological barriers, and social barriers, then communication is considered effective. Successful patient care and treatment depend entirely on the patient and family, understanding the information that the doctor delivers to them. As a result, patients get better knowledge and understanding, comply with the treatment, and are willing to follow what the doctor suggests.

There are many aspects of sensitive cultural communication competencies that must be trained and practiced by doctors as providers of health services at all times, including:

- Prioritize cultural communication competencies regarding sensitive and competent matters.

- Emphasize the importance of understanding cultural variations and how to communicate them

- Encourage the patient to ask questions so that the patient understands the condition that is happening.

- $\quad$ Stimulating patients displaying sensitive cultural expressions

- Find out how patients communicate sensitive culture and how to deal with it so that it can lead to better patient care.

- To achieve the doctor's adherence, collaborate with his family, and use communication channels that can be accessed by both parties.

\section{References}

[1] Gibson Robert, 2002, Intercultural Business Communication, Oxford, Oxford University Press.

[2] Harrington ,Nancy Grant, 2015, Health Communication, theory, method and Application, New York:Routledge.

[3] Al-Muqsith, 2016. Etika Profesi Kedokteran. Unimal

[4] U.S Department of Health and Human Services, Office of Minor Health, 2001, Final Report: National Standards for Culturally and Linguistically Apropriate Service in Health Care. 
[5] Rengganis, Baiq Santi, 2019. Handout of Intercultural Communication. UIN Mataram

[6] Dosenpsikologi.com, 2018. Hubungan antara Persepsi dengan Latar Budaya 